Final Report to U.S. Department of Energy

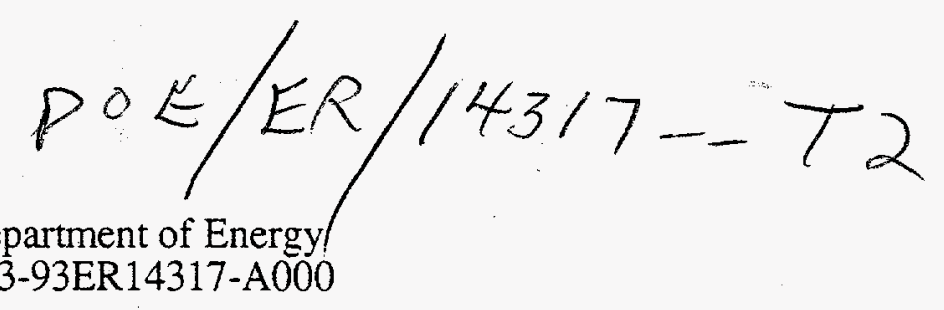

\title{
Structure and Modeling of the Three Dimensional Boundary Layer on a Rotating Disk
}

\author{
by John K. Eaton \\ Department of Mechanical Engineering \\ Stanford University
}

December 1996

\section{Introduction}

Almost all practical turbulent flows include three dimensional boundary layers (3DTBL's), and in many cases, the 3DTBL is the dominant feature of the flow. A boundary layer is defined as a thin layer adjacent to the surface in which the velocity drops rapidly from the freestream value to zero at the wall. A 3D boundary layer is one in which the flow direction also changes rapidly approaching the wall. This change in the flow direction called "skewing" is caused by transverse pressure gradients, centrifugal forces, or motion of the surface. Most research on turbulent boundary layers has been done in simple two dimensional flows in carefully controlled wind tunnels. Such boundary layers are now well understood, and excellent models are available describing both the fluid mechanics and heat transfer behavior. Recent fluid mechanics studies have shown that skewing can have a pronounced effect on the boundary layer turbulence. Models based on eddy-viscosity concepts fail, and more complex stress transport models cannot capture the reduction of turbulent mixing that usually accompanies skewing. It was unknown prior to the present study what effect the skewing might have on turbulent heat transfer. It was suspected that turbulent heat transport would be reduced in analogy to the reductions of turbulent shear stress. It was also unknown how the skewing would effect the turbulent Prandtl number, a quantity which is embedded in most turbulent heat transfer prediction schemes.

The objectives of the present study were then to study the surface heat transfer rate and the turbulent heat flux in a simple three dimensional boundary layer. In particular, the research addressed the heat transfer from a heated disk rotating in an otherwise quiescent environment. This flow is both a very simple 3DTBL and of practical significance to the rotating equipment industry. Also, the fluid mechanics aspect of this flow was the subject of a very detailed study under previous DOE funding (Littell and Eaton, 1994, Chiang and Eaton, 1996). The fluid mechanics measurements led to the now widely adopted model used to explain the reduction in turbulent stresses by skewing (Eaton, 1995). The present
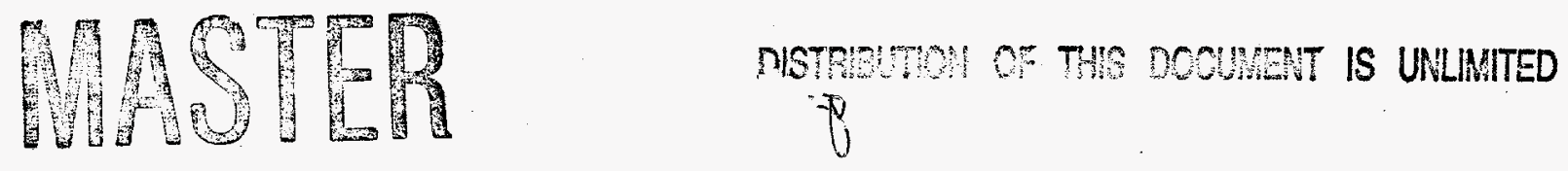


\section{DISCLAIMER}

This report was prepared as an account of work sponsored by an agency of the United States Government. Neither the United States Government nor any agency thereof, nor any of their employees, make any warranty, express or implied, or assumes any legal liability or responsibility for the accuracy, completeness, or usefulness of any information, apparatus, product, or process disclosed, or represents that its use would not infringe privately owned rights. Reference herein to any specific commercial product, process, or service by trade name, trademark, manufacturer, or otherwise does not necessarily constitute or imply its endorsement, recommendation, or favoring by the United States Government or any agency thereof. The views and opinions of authors expressed herein do not necessarily state or reflect those of the United States Government or any agency thereof. 


\section{DISCLAMMER}

Portions of this document may be illegible in electronic image products. Images are produced from the best available original document. 
measurements were intended to provide an equally detailed description of the turbulent heat transport behavior in the same flow.

\section{Experimental Techniques}

The experiments were performed in the air-flow rotating disk apparatus described by Littell and Eaton (1994). A new disk illustrated in Figure 1 was constructed for the heat transfer measurements. The $1 \mathrm{~m}$ diameter disk has a type 304 stainless steel surface plate 1 $\mathrm{mm}$ thick. Kapton thermofoil heaters capable of supplying a uniform heat flux of $1 \mathrm{~kW} / \mathrm{m}^{2}$ over most of the area of the disk are attached to the steel using pressure sensitive adhesive. An insulating balsa wood disk $15 \mathrm{~mm}$ thick lies below the heater. Pressure sensitive adhesive is used between the heaters and balsa as well. For structural support a $15 \mathrm{~mm}$ thick aluminum disk is attached to the balsa with contact cement and epoxy. Measurements of the disk surface temperatures can be made throughout the disk using the 40 copper-constantan thermocouples epoxied to the interior surfaces of the steel and aluminum. For the largest heat fluxes used, approximately $600 \mathrm{~W} / \mathrm{m}^{2}$, the temperature drop across the epoxy substrate and stainless steel surface was less than $0.1^{\circ} \mathrm{C}$ and even less across the thickness of the aluminum.

The kapton heaters were designed to provide a uniform heat flux, but due to the nature of the constant heat flux boundary condition, disk temperatures close to the center of the disk reach $55^{\circ} \mathrm{C}$ when temperatures at the outer radii are $30^{\circ} \mathrm{C}$ for runs at high rpm. This exceeds a tolerable temperature difference for a constant properties assumption. To solve this problem, the disk was split into three different annular regions. The inner disk with a $7.5 \mathrm{~cm}$ radius is unheated. The region from $7.5 \mathrm{~cm}$ to $20 \mathrm{~cm}$ radius is heated by the inner heater and from $20 \mathrm{~cm}$ to $48 \mathrm{~cm}$ by the outer heater. For runs at high Reynolds numbers the inner heat flux can be reduced to keep the maximum temperature difference to below $20^{\circ} \mathrm{C}$ which keeps property variations below $10 \%$.

The shroud surrounding the bottom of the disk forms a $120 \mathrm{~cm}$ diameter by $10 \mathrm{~cm}$ high cavity. The shroud walls are insulated with styrofoam and the temperature in the shroud cavity is controlled to reduce backlosses and maintain the steady state of the system. The cavity temperanure is held within $+1-0.1^{\circ} \mathrm{C}$ of the desired value by a closed-loop controller implemented on the laboratory computer. The control system uses a thermocouple as the sensor and a DC foil heater as the active element. The strong flows induced in the cavity by the disk insure that the temperature remains very uniform.

Measurements of the turbulent heat flux were made using the three wire sensor illustrated in Figure 2. Two of the wires form a conventional $x$-array hotwire, used to measure two velocity components. The third wire was a cold-wire for temperature 
measurement located just ahead of the crossing of the velocity measurement wires. The probe was custom built using $2.5 \mu \mathrm{m}$ diameter tungsten wires, plated and etched to a length of $0.6 \mathrm{~mm}$. Frequency compensation was accomplished using a digital filtering technique with the required parameters measured using a unique impulsive flow device. The measurement technique was tested by measuring the turbulent stresses in the heated boundary layer. These measurements agreed well with those previously.measured in isothermal flow by Littell and Eaton. In addition, the fluctuating temperature measurements were corroborated by measurements using a $1.0 \mathrm{~mm}$ diameter tungsten probe which had much better frequency response. Both of these measurements served to validate the frequency compensation șcheme.

\section{Results}

Figure 3 shows the local Nusselt number measured on the disk for a range of Reynolds numbers. The data show excellent agreement with previous studies of both laminar and turbulent disk boundary layers. These comparisons indicate that the boundary conditions are well established and that the measurement systems work correctly. The actually heat transfer measurements don't supply any new information, but do corroborate previous results.

The more important results are the boundary layer data including temperature and turbulent heat flux profiles. Figure 4 shows three temperature profiles all measured in the laminar boundary layer. The profiles collapse very well onto the analytical solution. which is plotted as a solid line. This indicates the consistency of the boundary conditions and the accuracy of the measurements. Figure 5 shows the turbulent boundary layer temperature profiles for two Reynolds numbers plotted in logarithmic wall coordinates. The profiles show the presence of a $\log$ region extending to $y+=300$. The constants $k$ and $C$ for each profile were found by least squares fit and do not agree with those found in $2 \mathrm{D}$ flat plate boundary layers where typical values as $k=0.48$ and $C=2.0$. In the disk boundary layer, $\mathrm{k}=3.4$ and 3.7 and $\mathrm{C}=-1.9$ and -2.9 for $\mathrm{Re}=6.5 \mathrm{e} 5$ and $1.0 \mathrm{e} 6$, respectively. $\mathrm{A}$ striking feature in these profiles is the presence of a wake region in the outer layer. One important feature of the velocity boundary layer is that there is no significant wake.

Profiles of the fluctuating temperature, $t^{\prime}$ measured with the 1 micron coldwire are shown in Figure 6. A slight Reynolds number dependence is evident, probably due to the difference in the thermal boundary condition between the two cases. In the higher Reynolds number case, the laminar and transition regions of the flow, which have smaller heat transfer coefficients and hence higher surface temperatures for our constant heat flux 
surface, occur at smaller radii. This leaves a longer development length for the turbulence before it reaches the probe. Hence, the flow will have forgotten some of the high temperatures it saw it the hotter laminar and transition regions. The $t^{\prime}$ values are similar to $2 \mathrm{D}$ experimental values but the shape of the profile is different; the disk measurements show an unexpected bulge in the outer layer. This bulge is probably due to the boundary condition as explained above.

Figure 7 shows the three turbulent heat flux components at a Reynolds number of $1,000,000$. The most important flux in this case is the wall normal flux, $\overline{v^{\prime} \theta^{\prime}}$. While the azimuthal component $\overline{u^{\prime} \theta^{\prime}}$ is quite large, there is no azimuthal gradient of the flux, so there is no net heat transport. Figure 8 shows the correlation coefficient between vertical velocity fluctuations and temperature fluctuations. The outer layer values are in the same range as those found in $2 \mathrm{D}$ boundary layers, but the correlation coefficient falls off closer to the wall. This suggests that the turbulence structure is less effective than a $2 \mathrm{D}$ boundary layer at producing heat flux. An alternative interpretation is that the turbulence is more random in character. This conclusion is supported by the anisotropy parameter $\left(\overline{\left(u^{\prime 2}\right.}+\overline{w^{\prime 2}}\right) / \overline{v^{\prime 2}}$ shown in Figure 9. This parameter has a value of 2 in isotropic turbulence and is typically around 5 or 6 in 2D boundary layers. Clearly, the value is closer to the isotropic level in the inner half of the boundary layer.

The structural parameters $A_{\theta}$ is commonly used in heat flux models and in the present case show substantial differences between $2 \mathrm{D}$ and $3 \mathrm{D}$ boundary layers. $A_{\theta}$ is defined as: $A_{\theta}=\frac{\overline{v^{\prime} \theta^{\prime}}}{\theta^{\prime} k}$

where $\mathbf{v}^{\prime} \theta^{\prime}$ is the turbulent heat flux, $\theta^{\prime}$ is the rms temperature, and $\mathrm{k}$ is the turbulent kinetic energy. It is a measure of the efficiency of the turbulence at producing turbulent heat flux. $A_{\theta}$ has a constant value around 0.22 in 2DTBLs. In our flow it is much lower than this in the inner layer but reaches a constant value of 0.16 above $y / \delta_{99}>0.2$.

The turbulent Prandtl number data $\left(\mathrm{Pr}_{t}\right)$ also show evidence of structural distortion by the three dimensionality as seen in Figure 10 which compares the present data to three flat plate experiments. Calculation of $\mathrm{Pr}_{\mathrm{t}}$ requires differentiation of the measured mean velocity and temperature profiles. Therefore, the data have more scatter than the direct measurements. Nevertheless, there is a clear trend of falling $\operatorname{Pr}_{t}$ in the outer layer. This can be contrasted to $2 \mathrm{D}$ boundary layer data which show the $\operatorname{Pr}_{\mathrm{t}}$ remaining nearly constant across the boundary layer. Previous measurements have shown that outer layer momentum 
transfer becomes less effective in three dimensional boundary layers. The $\operatorname{Pr}_{t}$ data indicate that the eddies' ability to transport heat is less effected by the three dimensionality.

The results demonstrate that structural distortion by three dimensional mean flow is large enough that the effects should probably be accounted for in refined turbulence models.

\section{Publications}

There have been four publications resulting from the work under this grant, Elkins and Eaton, 1994, Eaton (1995), Chiang and Eaton (1996), and Elkins and Eaton (1997). In addition, a report derived from Chris Elkins $\mathrm{Ph} . \mathrm{D}$. thesis is in preparation. Additional journal articles describing the turbulent heat flux measurements will be prepared after completion of the report.

\section{References}

Chiang, C. and Eaton, J.K. (1996) "An experimental study of the effects of threedimensionality on the near wall turbulence structures using flow visualization," Expts. in Fluids, 20 266-272.

Eaton, J.K. (1995) "Effects of mean flow three dimensionality on turbulent boundary-layer structure," AIAA J. 33, 2020-2025.

Elkins, C. J. and Eaton, J.K. (1994) "Heat transfer meașurements in the boundary layer on a rotating disk," AIAA/ASME Thermophysics and Heat Transfer Conference, Colorado Springs.

Elkins, C.J. and Eaton, J.K. (1997) "Turbulent heat flux measurements on a rotating disk," Eleventh Symposium on Turbulent Shear Flows, Grenoble.

Littell, H.S. and Eaton, J.K. (1994) "Turbulence characteristics of the boundary layer on a rotating disk," J. Fluid Mech. 266, 175-207. 


\section{HEAT TRANSFER DISK}

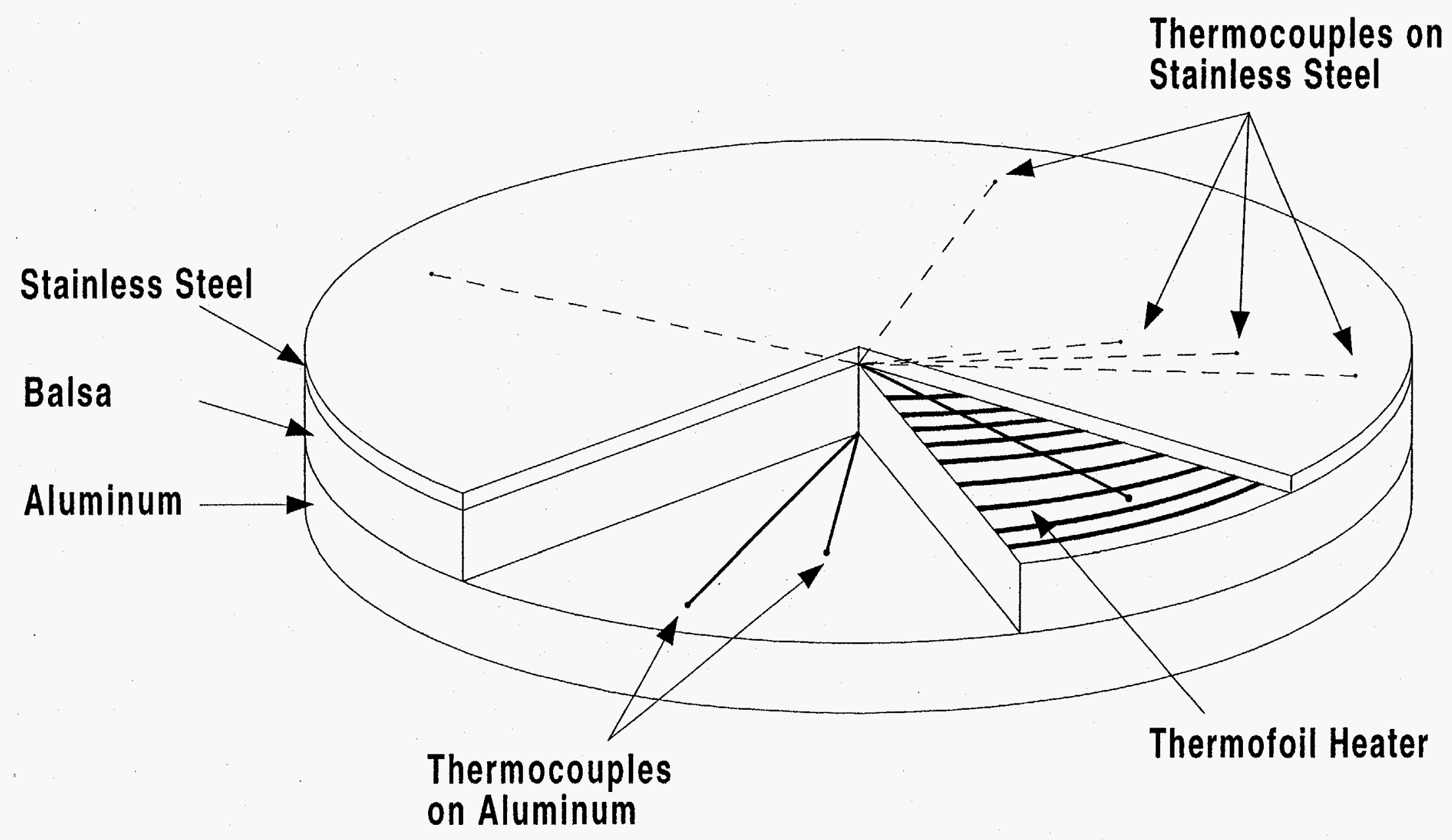



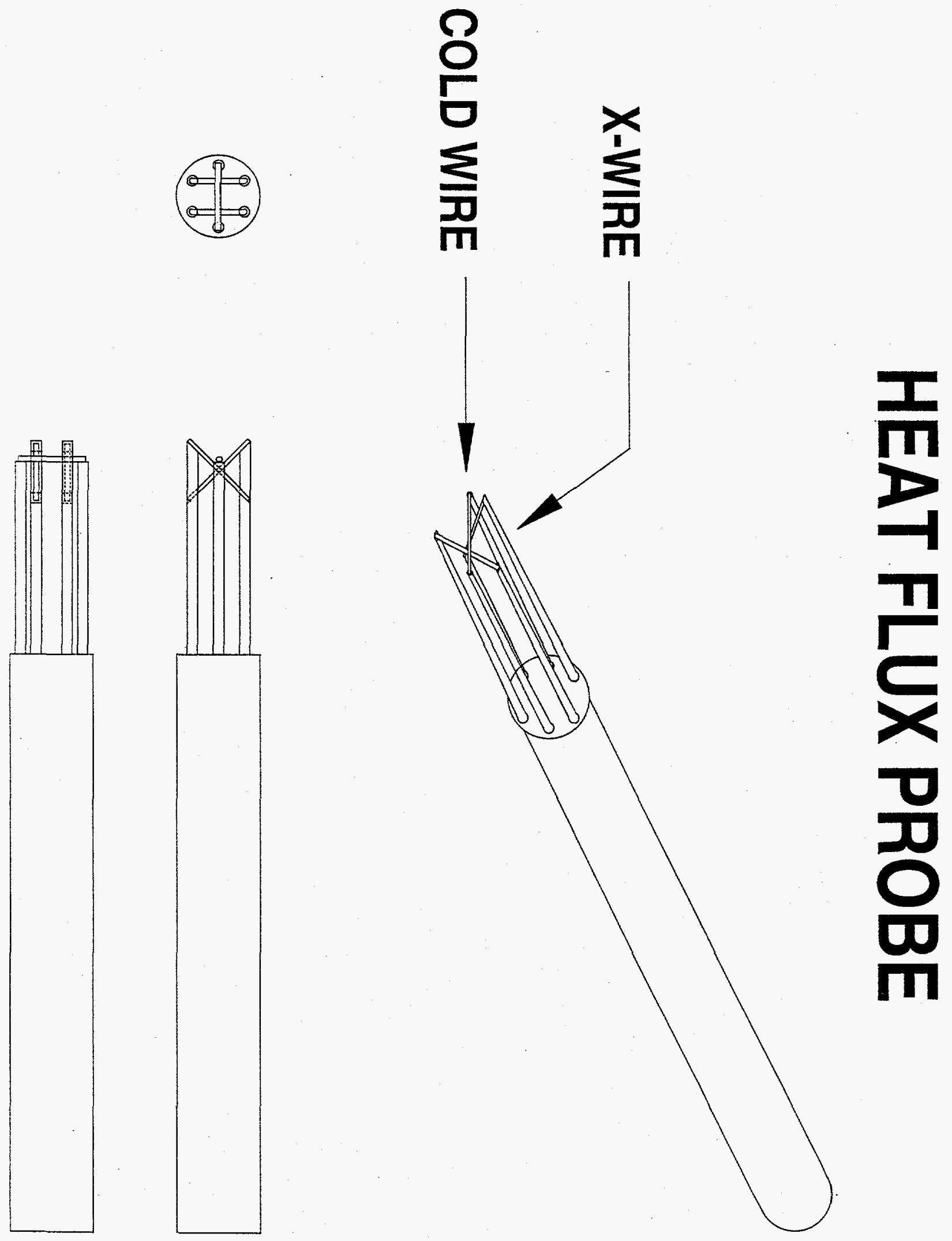


\section{BEHAVIOR OF LOCAL NUSSELT NUMBER WITH REYNOLDS NUMBER}

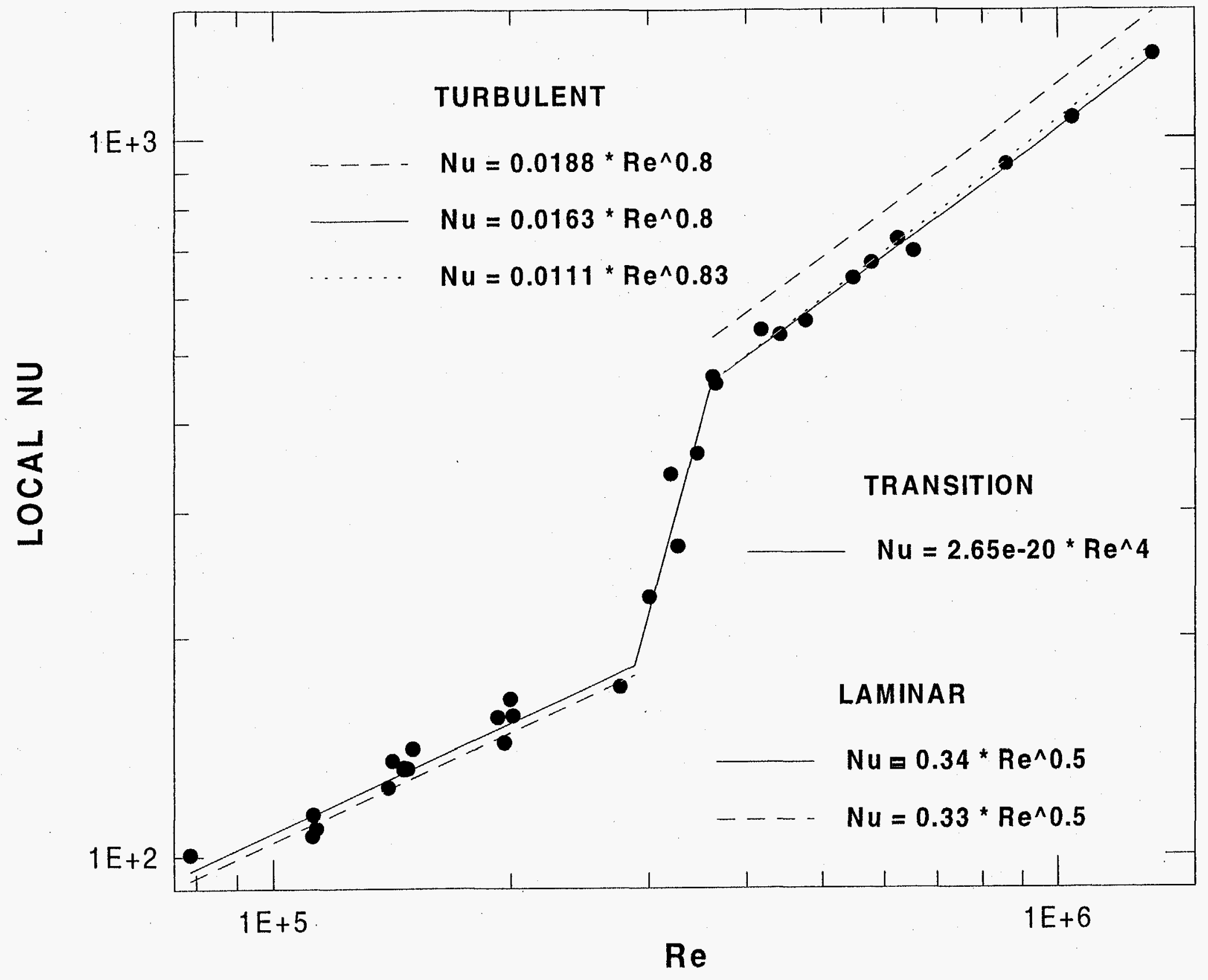


$Y \star S Q R T$ (omega/nu)

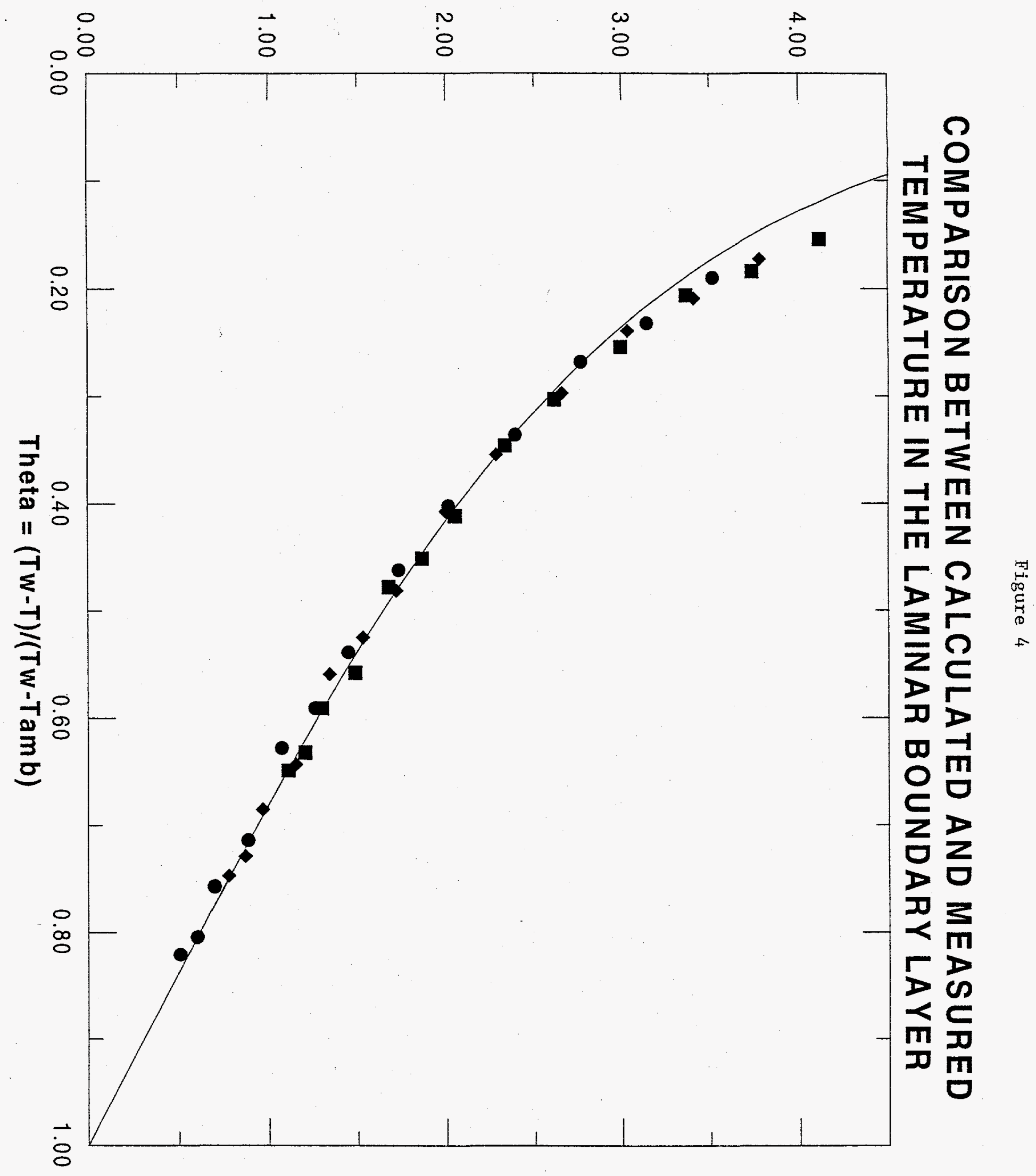




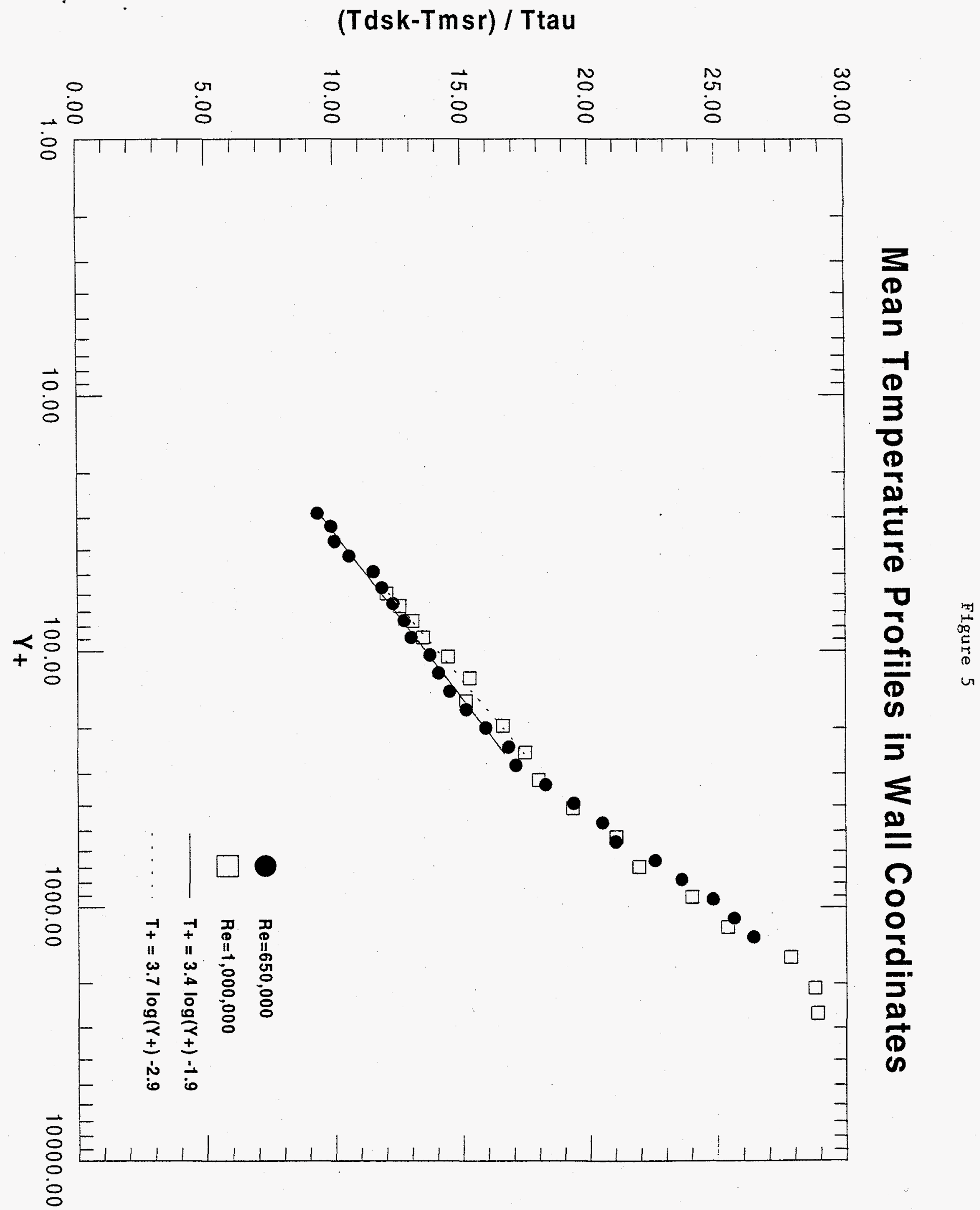




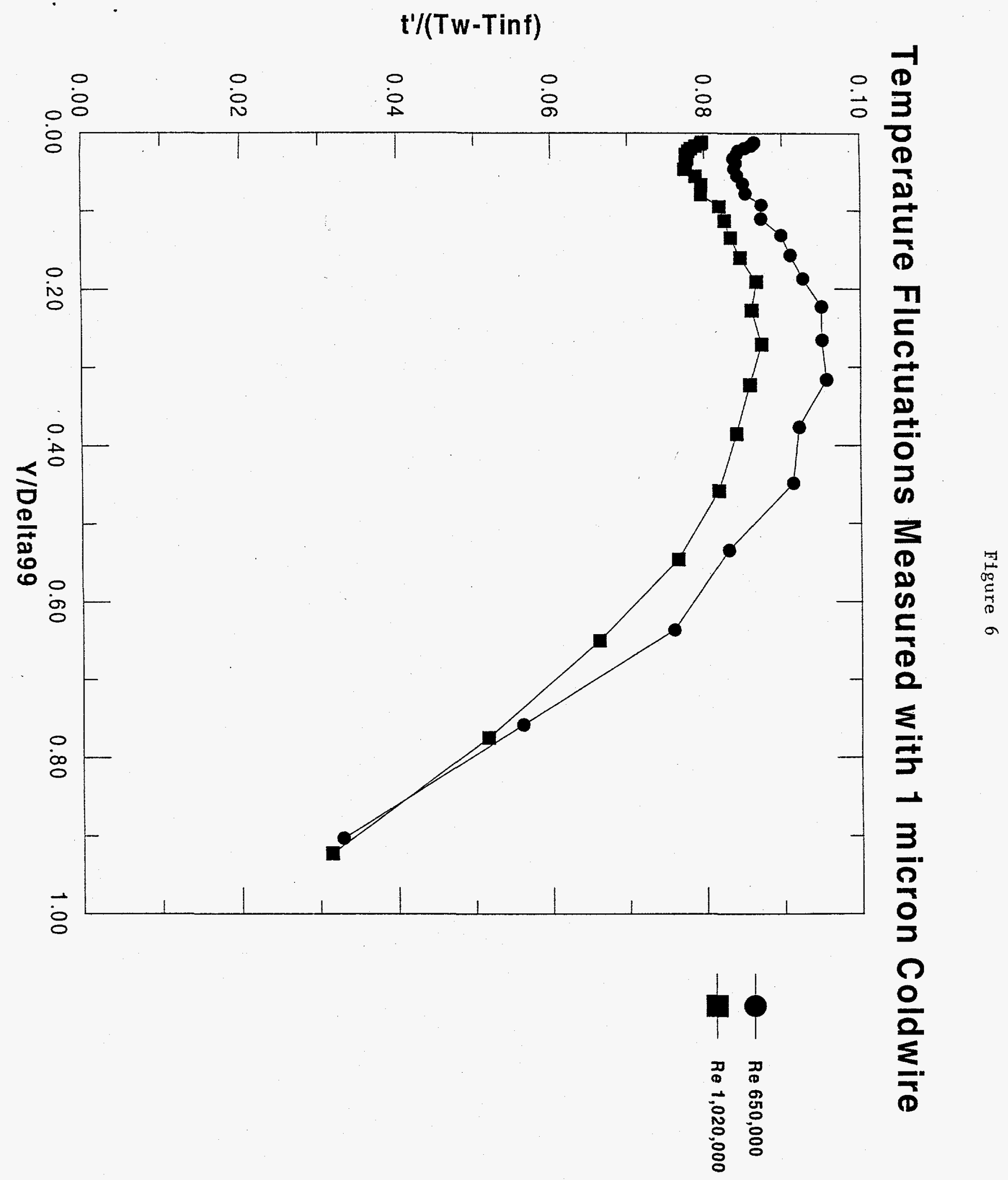


$-u^{\prime} t^{\prime} / U \operatorname{tau}{ }^{\star} T \operatorname{tau}, v^{\prime} t^{\prime} / U \operatorname{tau}{ }^{*} T \operatorname{Ttau},-w^{\prime} t^{\prime} /$ Utau*Ttau

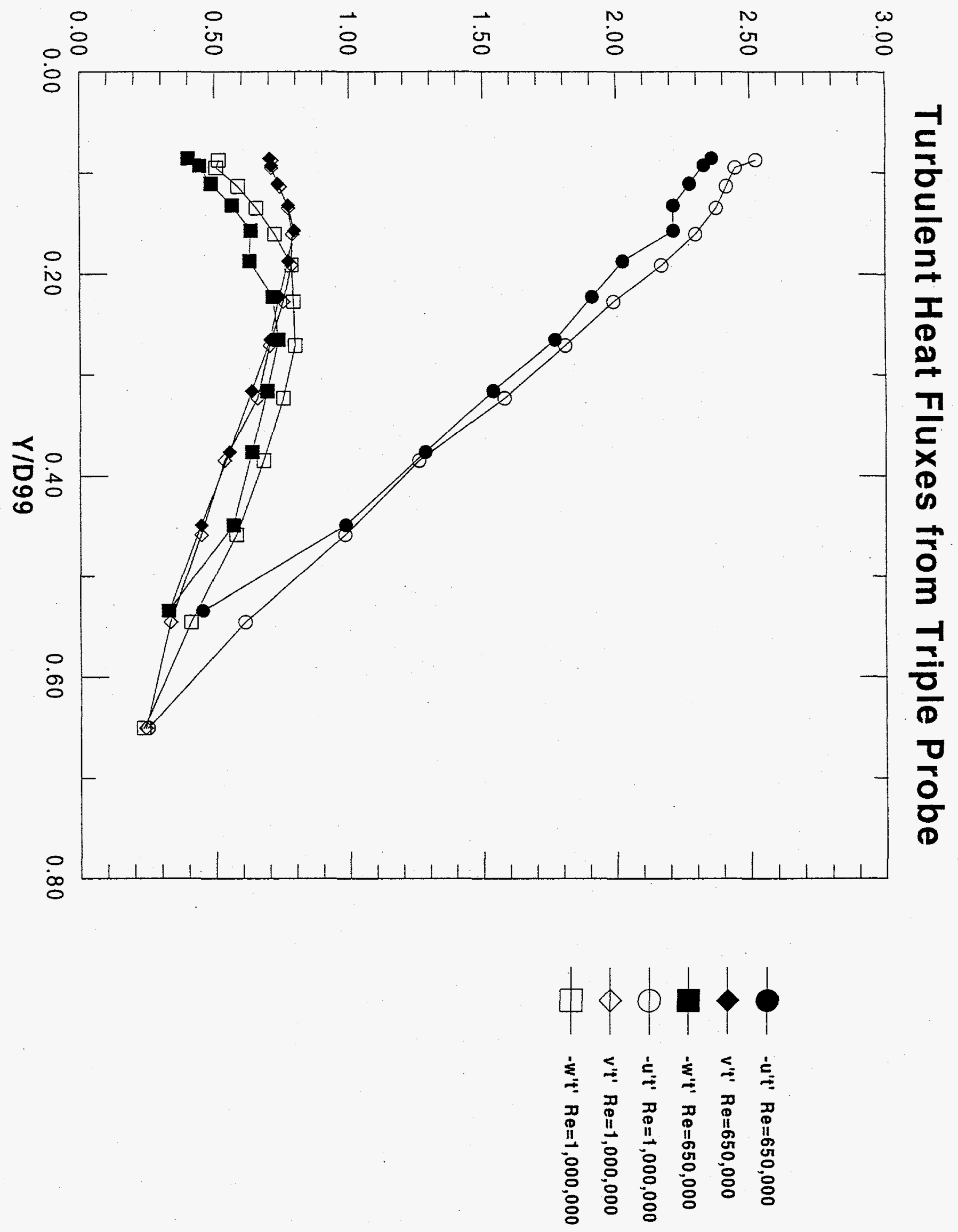




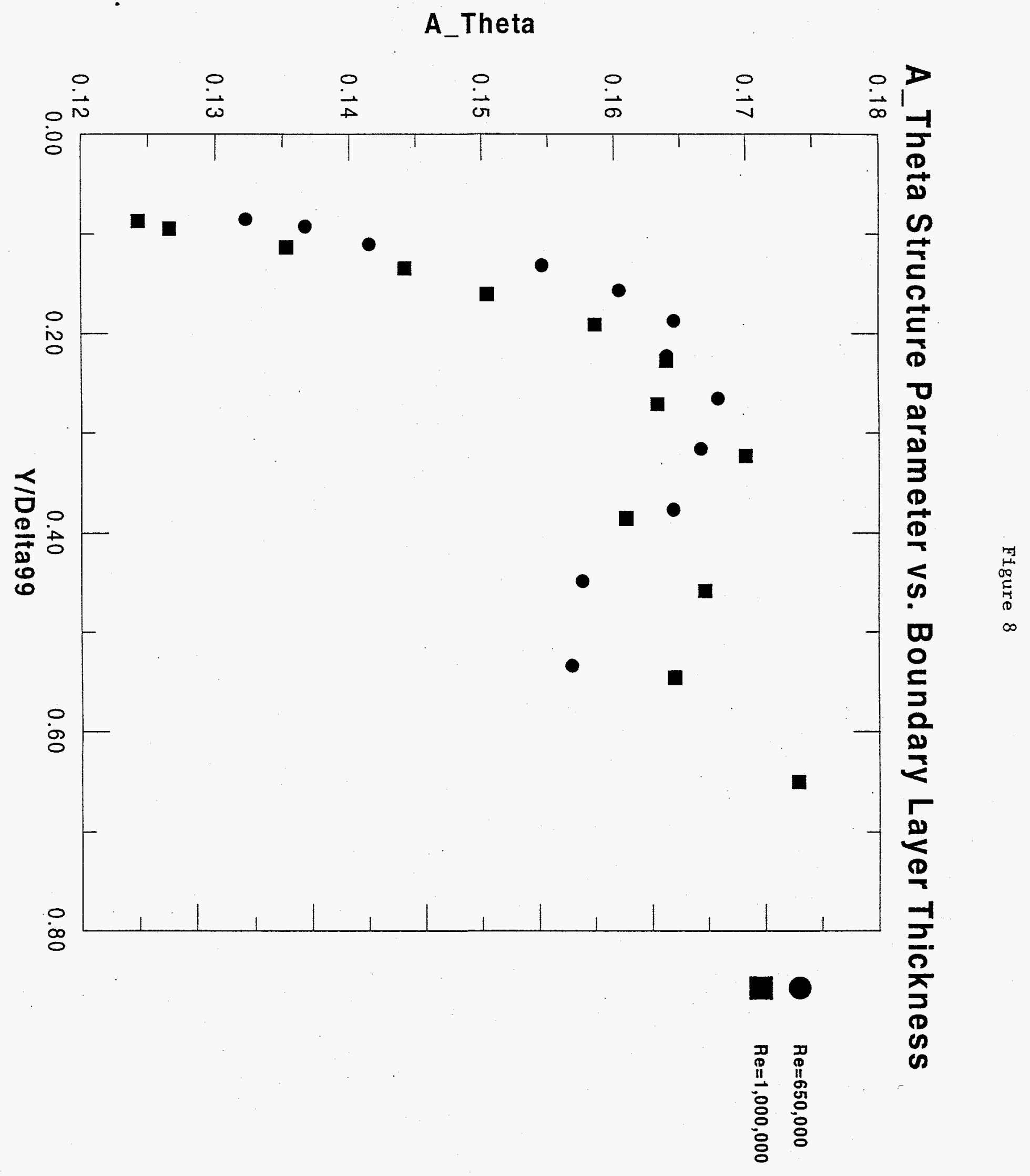




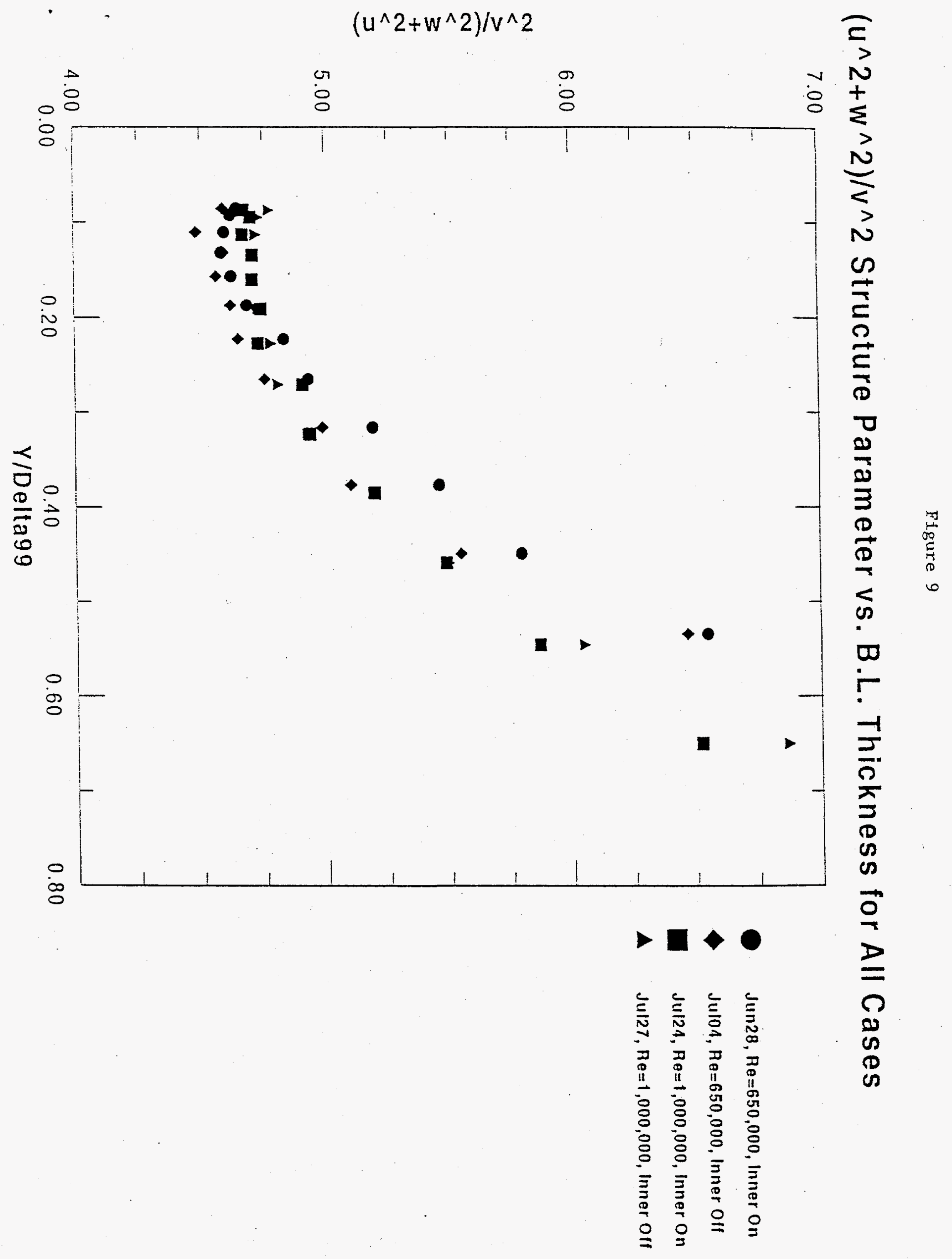


Turbulent Prandtl Number -- Rotating Disk Compared to Flat Plate Studies

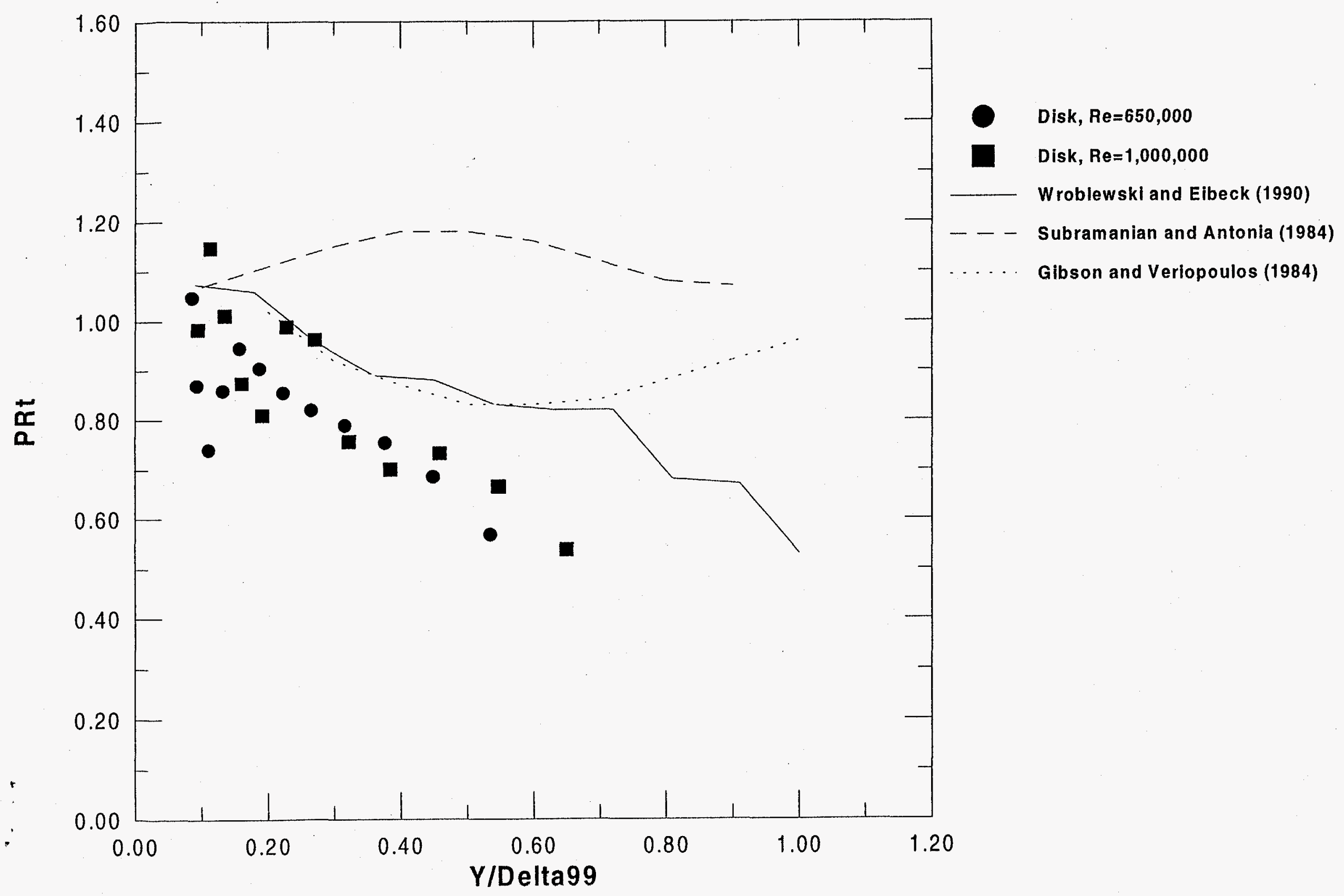

